\title{
Intuitionistic Fuzzy Optimization Technique in Agricultural Production Planning: A Small Farm Holder Perspective
}

\author{
S. K. Bharati \\ Department of Mathematics, \\ Banaras Hindu University, Varanasi- 221005
}

\author{
S. R. Singh \\ Department of Mathematics, \\ Banaras Hindu University, Varanasi- 221005
}

\begin{abstract}
Present paper is an application study of intuitionistic fuzzy optimization technique in agricultural production planning problem particularly a case of smallholder farmer in north Bihar, India. Generally, the crop planning problem is formulated as linear programming problems. but in realistic situation there are many uncertain factors in agricultural production planning problems and hence future profits for crop are imprecise and uncertain values. Therefore, we propose a model of crop planning using intuitionistic fuzzy optimization technique.
\end{abstract}

\section{General Terms}

Multi-Objective linear programming, Crop production planning.

\section{Keywords}

Multi-Objective linear programming, Fractional programming approach, Intuitionistic fuzzy sets, Intuitionistic fuzzy optimization.

\section{INTRODUCTION}

In agricultural production planning problems, one of the major objective is to maximize the profit under minimum investment with limited land. But a general problem of agricultural production planning is not limited to profit optimization with cost minimization. A realistic crop production planning problem comprise of several objectives like optimization of input resource like: man hours, machine hours, fertilizers, water requirement and many more. These objectives are also conflicting in nature. Further, the cost of cultivation and prices of food grains are fluctuating in nature as these depend on many uncontrolled parameters. Thus, these constraints are imprecise, vague and uncertain in nature. Due to such features of crop production problems, the crisp multi-objective methods are not very suitable for developing the cropping models. Thus Zimmermann [23] first used the concept of fuzzy set given by Zadeh [22] and studied fuzzy programming and linear programming with several objectives. Further, many authors like Tanaka and Asai [18], Luhandjula [11], Itoh et.al [19], Toyonaga et al [20], Sarkar et al [15], Sharma et al [16]. Garg and Singh [10], worked on crop planning models in fuzzy environment. As the theory of fuzzy sets was extended to intuitionistic fuzzy sets theory by Atanassov [1, 2], Angelov [3] studied the optimization in an intuitionistic fuzzy environment. The theory of linear programming in intuitionistic fuzzy set was further enriched by several authors as Dubey et al $[8,9]$, Jana and Roy [4] Luo and Yu [21]. Nachammai Thangaraj [13] and Nagoorgani [14]. Recently Bharati and Singh [6, 7], have studied the multi-objective linear programming problems in intuitionistic fuzzy environment.

Agriculture is the one of the vital sectors of Indian economy. Sixty seven per cent of India's population lives in rural areas, and three-fourth of the people of rural populations depend on agriculture and allied activities for their livelihoods (Census of India. 2011). Although the contribution of agriculture to India's gross domestic product (GDP) is $15 \%$, but this sector is the main source of employment in Indian economy, comprising 55\% of the country labour force (Census of India. 2011). Major part of agriculture in the country is rain fed, extending to over 87 millimetres per hectare and constituting nearly $61 \%$ of net cultivated area. Hence monsoons play a critical role in Indian agriculture in determining whether the harvest will be bumper, average or poor in any given year. Bihar lies in the river plains of the basin of the Ganga. It is endowed with fertile alluvial soil with abundant water resources, especially ground water resources. This makes the agriculture of Bihar rich and diverse. Rice, wheat, and maize are the major cereal crops of Bihar. Arhar, urad, moong, gram, pea, lentils and khesaria are some of the pulses cultivated in Bihar. Bihar is one of major producer of mango, banana, and guava. Sugar cane and jute are two other major cash crops of Bihar.

However, rice is cultivated in almost all the districts of Bihar. Autumn rice, agahani rice and summer rice are three different varieties of rice grown at three different times of the year. The average production of rice in Bihar is around 5 million tonnes each year. Some five decades back wheat cultivated was very restricted in Bihar. After green resolution success farmers started growing wheat on a larger scale and thus wheat now occupies the status of major crop of the Rabi season. The average annual wheat production is approximately 40-45 tonnes. Maize is also cultivated with the average annual production level of approximately 1.5 million tonnes and a steady positive trend in production. The leading producer districts are Khagaria and Saharsa. Pulses such as moong, Arhar, peas and khesaria are grown more in southern Bihar than in northern Bihar. The leading districts are Patna, Bhojpur, Aurngabad and Nalanda. The total area under vegetables cultivation is currently about $11 \%$ of the state gross sown area and now have increasing trend. The important vegetables crops include potato, onion, tomato, cauliflower and Brinjal. Hajipur in Vaishali is famous for an early variety of cauliflower that reaches market in the last week of September.. Apart from Patna and Nalanda where vegetables production is quite extensive, the other districts with high shares in total vegetables production are Vaishali, Muzaffarpur, west Champaran, east Champaran, Katihar and Begusarai. 
Bihar has a geographical area of 9,360,000 hectares with three important agro-climate zones: north-west, north-east and south. The north-west zones has 13 district and receives an annual rainfall of $1040-1450 \mathrm{~mm}$. The soil is mostly loam and sandy loam. The north-east zones has 8 districts, it receives rainfall ranging from $1200-1700 \mathrm{~mm}$ and has loam and clay loam soils. Finally the south zone (17 districts) receives an average annual rainfall of 990-1300 mm. Its soils are sandy loam, clay and clay loam. The average rainfall in Bihar is $1052.6 \mathrm{~mm}$. The rainfall in Bihar is largely due to southwest monsoons which accounts for around $85 \%$ of total rainfall in the state.

First, we introduce basic terms and definition related to the paper and then fuzzy optimization technique, intuitionistic fuzzy optimization technique, crop production planning problem and mathematical formulation of the problems and finally follows the conclusion of studies.

\section{PRELIMINARIES \\ 2.1 Multi objective linear programming problem}

In general, a multi objective optimization problem with $\mathrm{p}$ objectives, $\mathrm{q}$ constraints and $\mathrm{n}$ decision variables, is follows as:

$$
\left.\begin{array}{c}
\text { Max }\left\{f_{1}, f_{2}, \ldots, f_{p}\right\} \\
\text { Such that } \\
g_{j}(X) \leq 0, j=1,2, \ldots, q \cdot \\
X=\left\{x_{1}, x_{2}, \ldots, x_{n}\right\} \\
x_{i} \geq 0, \quad i=1,2, \ldots, n
\end{array}\right\}
$$

\subsection{Complete solution}

$x^{0}$ is said to be a complete optimal solution for problem (1) if there exist $x^{0} \in X$ such that $f_{k}\left(x^{0}\right) \leq f_{k}(x)$ for all $x \in X$. However, in general such complete optimal solutions that simultaneously maximize all of the multiple-objective function do not exist, especially when the objective functions are conflicting in nature. Thus instead of a complete optimal solution a solution concept, called Pareto optimality was introduced in multi-objective programming.

\subsection{Pareto-Optimality}

$x^{0} \in X$ is said to be a Pareto optimal solution for (1) if there does not exist another $x \in X$ such that $f_{k}\left(x^{0}\right) \leq f_{k}(x)$ for all $k=1,2, \ldots, p$ and $f_{j}\left(x^{0}\right)<f_{j}(x)$ for at least one $j=1,2, \ldots, p$.

\subsection{Linear fractional programming approach}

Let there be $\mathrm{s}$ objective out of $\mathrm{k}$ objectives such that their ratio is to maximized. For simplicity let us restrict number of such objectives to two and let these two linear objectives are $f_{p}(x)>0$ and $f_{q}(x)>0$ whose ratio forms a new objective function, giving rise to linear fractional programming as Maximize $\frac{f_{p}(x)}{f_{q}(x)}$,

\section{Proposition}

As we assume that $f_{p}(x)>0$ and $f_{q}(x)>0$, therefore (2) is equivalent to

$$
\left.\begin{array}{c}
\text { Maximize } f_{p}(x)-f_{q}(x) \\
\text { Such that } \\
f_{p}(x)-\sigma f_{q}(x)>0
\end{array}\right\}
$$

Where $\sigma$ is a positive real number, which is a restriction that the ratio should always greater than a level $\sigma$.

\subsection{Intuitionistic fuzzy sets}

An intuitionistic fuzzy sets $\tilde{A}$ assigns to each element $x$ of the universe $X$ a membership degree $\mu_{\tilde{A}}(x) \in[0,1]$ and nonmembership degree $v_{\tilde{A}}(x) \in[0,1]$ such that $\mu_{\tilde{A}}(x)+$ $v_{\tilde{A}}(x) \leq 1$. A IFSs mathematically represented as $\left\{\left(x, \mu_{\tilde{A}}(x)\right.\right.$, $\left.\left.v_{\tilde{A}}(x)\right) \mid x \in X\right\}$ where, $1-\mu_{\tilde{A}}(x)-v_{\tilde{A}}(x)$ is called hesitancy margin.

\section{Example}

Let $A$ be set of countries with elected government and let $x$ be a member of $A$. Let $M(x)$ be the percentage of the electorate that voted for the government, $N(x)$ the percentage that voted against. If we take $\mu_{\tilde{A}}(x)=\frac{M(x)}{100}, v_{\tilde{A}}(x)=\frac{N(x)}{100}$, then $\mu_{\tilde{A}}(x)$ gives the degree of support, $v_{\tilde{A}}(x)$ the degree of opposition and $h(\tilde{A})=1-\mu_{\tilde{A}}(x)-v_{\tilde{A}}(x)$ stand for indeterminacy which is the portion that cast bad votes: invalid votes, abstinent.

\subsection{Intuitionistic Fuzzy Number}

An intuitionistic fuzzy set (IFS) $\tilde{A}=\left(\mu_{\tilde{A}}, v_{\tilde{A}}\right)$ of real numbers is said to be an intuitionistic fuzzy number if $\mu_{\tilde{A}}$ and $v_{\tilde{A}}$ are fuzzy numbers. Hence $\tilde{A}=\left(\mu_{\tilde{A}}, v_{\tilde{A}}\right)$ denotes an intuitionistic fuzzy number if $\mu_{\tilde{A}}$ and $v_{\tilde{A}}$ are fuzzy numbers with $v_{\tilde{A}} \leq \mu_{\widetilde{A}^{\mathrm{c}}}$, where $\mu_{\widetilde{A}^{\mathrm{c}}}$ denotes the complement of $\mu_{\tilde{A}}$.

Some operations on intuitionistic fuzzy sets are:

$$
\begin{aligned}
& \tilde{A} \cap \tilde{B}=\left\{\left(x, \min \left(\mu_{\tilde{A}}(x), \mu_{\tilde{B}}(x)\right), \max \left(v_{\tilde{A}}(x), v_{\tilde{B}}(x)\right)\right) \mid x \in X\right\} \\
& \tilde{A} \cup \tilde{B}=\left\{\left(x, \max \left(\mu_{\tilde{A}}(x), \mu_{\tilde{B}}(x)\right), \min \left(v_{\tilde{A}}(x), v_{\tilde{B}}(x)\right)\right) \mid x \in X\right\}
\end{aligned}
$$

\section{INTUITIONISTIC FUZZY OPTIMIZATION TECHNIQUE}

Consider the general optimization problem given as

$$
\left.\begin{array}{c}
\text { Max } f_{i}(x), \quad i=1,2, \ldots, p \\
\text { Such that } \\
g_{j}(x) \leq 0, \quad j=1,2, \ldots, q . \\
\quad x \geq 0
\end{array}\right\}
$$

Where, $x$ is decision variables, $f_{i}(x)$ denotes objective functions, $g_{j}(x)$ denotes the constraint functions, $p$ and $q$ respectively denotes the number of objective(s) and constraints. The solution of this crisp model must satisfy all constraints exactly.

In analogous fuzzy optimization model to the above problem, the degree of acceptance of objective(s) and constraints must is maximized respectively:

$$
\left.\begin{array}{c}
\widetilde{\operatorname{M}} f_{i}(x), \quad i=1,2, \ldots, p \\
\text { Such that } \\
g_{j}(x) \lesssim 0, \quad j=1,2, \ldots, q . \\
\quad x \geq 0
\end{array}\right\}
$$

Where $\widetilde{\text { Mın }}$ denotes fuzzy minimization and $\lesssim$ denotes fuzzy inequality. For solution of such system (5), Bellman and Zadeh [5] used fuzzy set maximize the degree of membership (acceptance) of the objective and constraints 


$$
\left.\begin{array}{c}
\operatorname{Max} \mu_{k}(x), \quad k=1,2, \ldots, p+q \\
\text { Such that } \\
0 \leq \mu_{k}(x) \leq 1 \\
x \geq 0
\end{array}\right\}
$$

Where $\mu_{k}(x)$ denotes the degree of satisfaction to respective fuzzy sets. As in fuzzy set the degree of non-membership is complement of membership, hence maximization of membership function will automatically minimize the nonmembership.

But in intuitionistic fuzzy set degree of rejection is defined simultaneously with the degree of acceptance and when both these degree are not complementary each other, hence IFS may give more general tool for describing this uncertainty based optimization model. Thus, intuitionistic fuzzy optimization (IFO) model for (6) is given as

$$
\begin{gathered}
\max _{x} \mu_{k}(x), \quad k=1,2, \ldots, p+q \\
\min _{x} v_{k}(x), k=1,2, \ldots, p+q \\
\text { Such that } \\
x \in X \\
\quad k=1,2, \ldots, p+q \\
v_{k}(x) \geq 0, \quad \begin{array}{c}
k \\
\mu_{k}(x) \geq v_{k}(x), k=1,2, \ldots, p+q \\
\mu_{k}(x)+v_{k}(x) \leq 1 \\
k=1,2, \ldots, p+q
\end{array}
\end{gathered}
$$

Where, $\mu_{k}(x)$ denotes the degree of acceptance of $x$ to the $k^{\text {th }}$ IFS and $v_{k}(x)$ denotes the degree of rejection of $x$ from the $k^{\text {th }}$ IFS. These IFS include intuitionistic fuzzy objective(s) and constraints.

Now the decision set $\widetilde{D}$ is defined as conjunction of intuitionistic fuzzy objective(s) and constraints is defined as

$$
\tilde{F} \cap \tilde{C}=\left\{\left\langle x, \min \left(\mu_{\tilde{F}}(x), \mu_{\tilde{C}}(x)\right), \max \left(v_{\tilde{F}}(x), v_{\tilde{C}}(x)\right)\right\rangle\right\},
$$

Where $\tilde{F}$ is integrated intuitionistic fuzzy objective and $\widetilde{C}$ denotes integrated intuitionistic fuzzy constraints and is defined as:

$$
\begin{gathered}
\tilde{F}=\left\{\left\langle x, \mu_{\tilde{F}}(x), v_{\tilde{F}}(x)\right\rangle \mid x \in X\right\}= \\
\bigcap_{i=1}^{p} \breve{F}^{i}=\left\{\left\langle x, \min _{i=1}^{p} \mu_{i}^{f}(x), \max _{i=1}^{p} v_{i}^{f}(x)\right\rangle \mid x \in X\right\}, \\
\tilde{C}=\left\{\left\langle x, \mu_{\tilde{C}}(x), v_{\tilde{C}}(x)\right\rangle \mid x \in X\right\}= \\
\bigcap_{i=1}^{q} \check{C}^{i}=\left\{\left\langle x, \min _{j=1}^{q} \mu_{j}^{g}(x), \max _{j=1}^{q} v_{j}^{g}(x)\right\rangle \mid x \in X\right\},
\end{gathered}
$$

And the intuitionistic fuzzy decision set (IFDS) denoted as $\widetilde{D}$ :

$$
\begin{gathered}
\widetilde{D}=\tilde{F} \cap \tilde{C}=\left\{\left\langle x, \mu_{\widetilde{D}}(x), v_{\widetilde{D}}(x)\right\rangle \mid x \in X\right\}, \quad \ldots,(9) \\
\mu_{\widetilde{D}}(x)=\min \left\{\mu_{\tilde{F}}(x), \mu_{\tilde{C}}(x)\right\}=\min _{k=1}^{p+q} \mu_{k}(x), \ldots(10) \\
v_{\widetilde{D}}(x)=\max \left\{v_{\tilde{F}}(x), v_{\tilde{C}}(x)\right\}=\max _{k=1}^{p+q} v_{k}(x), \ldots \text { (11) }
\end{gathered}
$$

where $\mu_{\widetilde{D}}(x)$ denotes the degree of acceptance of IFDS and $v_{\widetilde{D}}(x)$ denotes the degree of rejection of IFDS.

Further for the feasible solution the degree of acceptance of IFDS always is less than or equal to the degree of acceptance of any objective and constraint and the degree of rejection of IFDS always is more than or equal to the degree of rejection of any objective and constraint, ie.

$$
\begin{gathered}
\mu_{\widetilde{D}}(x) \leq \mu_{k}(x), \\
v_{\widetilde{D}}(x) \geq v_{k}(x), \\
\forall k=1,2, \ldots, p+q .
\end{gathered}
$$

Thus the above system can be transformed to the following system of inequalities:

$$
\left.\begin{array}{c}
\mu_{k}(x) \geq \alpha, k=1,2, \ldots, p+q \\
v_{k}(x) \leq \beta, k=1,2, \ldots, p+q \\
\alpha+\beta \leq 1 \\
\alpha \geq \beta \\
\beta \geq 0 \\
x \in X
\end{array}\right\}
$$

Where $\alpha$ denotes the minimum acceptable degree of objective(s) and constraints, and $\beta$ denotes the maximum degree of rejection of objective(s) and constraints.

Using the IFOP analogous to problem (5) transformed to the linear programming problem can be given as:

$$
\begin{gathered}
\text { Maximize }(\alpha-\beta) \\
\mu_{k}(x) \geq \alpha, k=1,2, \ldots, p+q \\
v_{k}(x) \leq \beta, k=1,2, \ldots, p+q \\
\alpha+\beta \leq 1 \\
\alpha \geq \beta \\
\beta \geq 0 \\
x \in X
\end{gathered}
$$

This can be easily solved by simplex method for solution of multi-objective linear programming problem by IFO.

Figure of the membership function and non- membership function for maximization type objective function are shown in figure (1) :

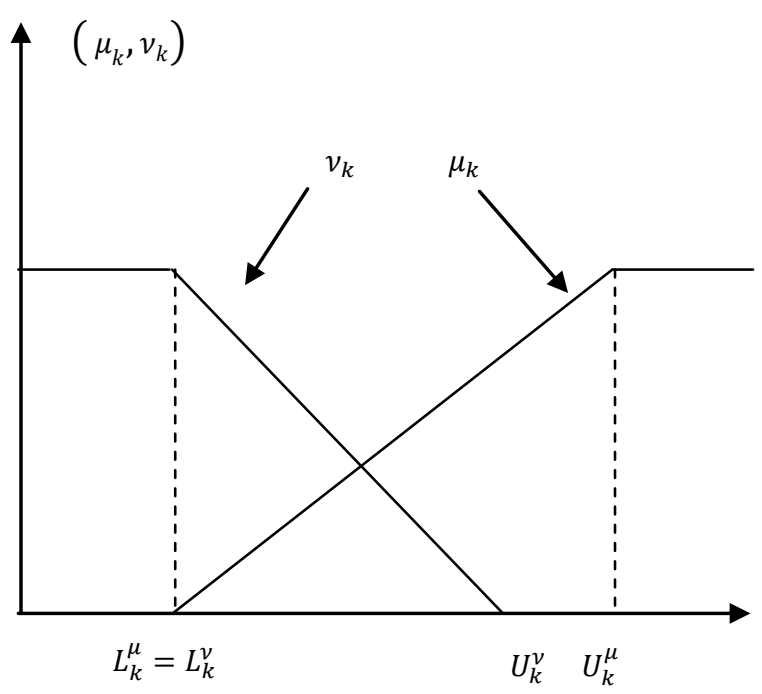

\section{CROP PRODUCTION PLANNING PROBLEM}

Let the number of crop be $n$ and let the decision variables be $x_{1}, x_{2}, \ldots \ldots \ldots x_{n}$, denote the cultivation for the crop $1,2, \ldots \ldots \ldots \ldots$. and $P_{i}, c_{i}, I_{i}$ and $w_{i}$ be production, profit, investment and labour (time) coefficient for cultivation per unit area for the crop $i$ respectively. Land is limited and hence $x_{1}+x_{2}+\ldots \ldots \ldots \ldots+x_{n}$ is always less than or equal to a fixed number (say $L$ ). Further, let $W$ be total labour (man-day). In order to maximize profit and minimize cost of the agricultural production, the problem is formulated as the multiobjective linear programming problem. 


$$
\begin{aligned}
& \operatorname{Max} \mathrm{z}_{1}=P_{1} x_{1}+P_{2} x_{2}+\ldots+P_{n} x_{n} \text { (production) } \\
& \operatorname{Max} z_{2}=c_{1} x_{1}+c_{2} x_{2}+, \ldots,+c_{n} x_{n} \quad \text { (Profit) } \\
& \text { Min } z_{3}=I_{1} x_{1}+I_{2} x_{2}+\ldots,+I_{n} x_{n} \text { (Investment) } \\
& \text { Suct that } \\
& \sum_{i=1}^{r \leq n} P_{i} x_{i} \geq P_{e} \text {, (Essential crop constraints) } \\
& x_{1}+x_{2}+, \ldots,+x_{n} \leq L \text {, (Land constraint) } \\
& w_{1} x_{1}+w_{2} x_{2}+, \ldots+, w_{n} x_{n} \leq W \text {, (Labour constraint) } \\
& x_{1}, x_{2}, \ldots \ldots \ldots x_{n} \geq 0 \text {. }
\end{aligned}
$$

The above multi-objective programming problem can be considered as linear fractional programming with a objective to optimize the efficiency of the system. We considered the optimization of ratio of profit $\left(z_{2}\right)$ with the investment $\left(z_{3}\right)$ as a fractional objective function. Further the sake of simplicity we assume the ratio as unity and hence the two objective $z_{2}$ and $z_{3}$ are reduced to a single objective $z_{2}-z_{3}$.

\section{COMPUTATIONAL ALGORITHM}

Using the above mentioned theorem and with the method by Anglev [3], we develop the following algorithm for getting solution of a multi objective programming problem in intuitionistic fuzzy environment:

Step1:Take one objective function out of given $\mathrm{k}$ objectives and solve it as a single objective subject to the given constraints. Form obtained solution vectors find the values of remaining (k-1) objective functions.

Step2: Continue the step 1 for remaining (k-1) objective functions. If all the solutions are same, then one of them is the optimal compromise solution.

Step3: Tabulate the solutions thus obtained in step1 and step2 to construct the Positive Ideal Solution (PIS) as given below.

\begin{tabular}{|c|ccccc|c|}
\hline & $f_{1}$ & $f_{2}$ & $f_{3}$ & $\ldots$ & $f_{k}$ & $X$ \\
\hline $\max f_{1}$ & $f_{1}^{*}$ & $f_{2}\left(X_{1}\right)$ & $f_{3}\left(X_{1}\right)$ & $\ldots$ & $f_{k}\left(X_{1}\right)$ & $X_{1}$ \\
$\max f_{2}$ & $f_{1}\left(X_{2}\right)$ & $f_{2}^{*}$ & $f_{3}\left(X_{2}\right)$ & $\ldots$ & $f_{k}\left(X_{2}\right)$ & $X_{2}$ \\
$\max f_{3}$ & $f_{1}\left(X_{3}\right)$ & $f_{2}\left(X_{3}\right)$ & $f_{3}^{*}$ &.. & $f_{k}\left(X_{3}\right)$ & $X_{3}$ \\
$\vdots$ & & & & & & $\vdots$ \\
$\vdots$ & & & & & & $\vdots$ \\
& & & & & & \\
$\max f_{k}$ & $f_{1}\left(X_{k}\right)$ & $f_{2}\left(X_{k}\right)$ & $f_{3}\left(X_{k}\right)$ & $\ldots$ & $f_{k}^{*}$ & $X_{k}$ \\
\hline & $f_{1}^{\prime}$ & $f_{2}^{\prime}$ & $f_{3}^{\prime}$ & $\ldots$ & $f_{k}^{\prime}$ & \\
\hline
\end{tabular}

Table 1 . Positive Ideal Solution

Step 4: From PIS, obtain the lower bounds and upper bounds for each objective functions, where $f_{k}^{*}$ and $f_{k}^{\prime}$ are the maximum, minimum values respectively.

Step 5: Set upper and lower bounds for each objective for degree of acceptance and degree of rejection corresponding to set of solutions obtained in step4.

For membership functions:

Upper and lower bound for membership functions

$$
\begin{gathered}
U_{k}^{\mu}=\max \left(Z_{k}\left(X_{r}\right)\right) \\
L_{k}^{\mu}=\min \left(Z_{k}\left(X_{r}\right)\right), \quad 0 \leq r \leq K
\end{gathered}
$$

For non -membership functions:

$$
U_{k}^{v}=U_{k}^{\mu}-\lambda\left(U_{k}^{\mu}-L_{k}^{\mu}\right), U_{k}^{v}=L_{k}^{\mu}, 0<\lambda<1 .
$$

In our problem, we have taken $\lambda=0.2$.

Step 6: MOLP problems (1) can be written as: Find $x$

\section{Such that}

$f_{k}(x) \geq \gtrsim g_{k}^{0}$, for every $\mathrm{k}$, where $g_{k}^{0}$ are aspirations levels given by decision maker. Here all objectives are conflicting nature, and hence here inequalities are taken as intuitionistic fuzzy inequalities.

Further, we define membership and non-membership function for the intuitionistic fuzzy inequalities in next step.

\section{Step 7: Construction of membership and non- membership functions}

Define the membership and non- membership function for the uncertain objective functions.

(i). For maximization of objective functions

$$
\begin{aligned}
& \mu_{k}\left(z_{k}(x)\right) \\
& =\left\{\begin{array}{cc}
1, & z_{k}(x) \geq u^{a c c} \\
\frac{z_{k}(x)-u^{a c c}}{u^{a c c}-l^{a c c},} & l^{a c c}<z_{k}(x)<u^{a c c} \\
0, & z_{k}(x) \leq l^{a c c}
\end{array}\right. \\
& v_{k}\left(z_{k}(x)\right) \\
& =\left\{\begin{array}{cc}
0, & z_{k}(x) \geq u^{r e j} \\
\frac{u^{r e j}-z_{k}(x)}{u^{r e j}-l^{r e j}} & l^{r e j}<z_{k}(x)<u^{r e j} \\
1, & z_{k}(x) \leq l^{r e j}
\end{array}\right.
\end{aligned}
$$

(ii). For minimization of objective functions

$$
\begin{gathered}
\mu_{k}\left(z_{k}(x)\right)=\left\{\begin{array}{cc}
0, & z_{k}(x) \geq u^{a c c} \\
\frac{u^{a c c}-z_{k}(x)}{u^{a c c}-l^{a c c}}, & l^{a c c}<z_{k}(x)<u^{a c c} \\
1, & z_{k}(x) \leq l^{a c c} \\
v_{k}\left(z_{k}(x)\right)
\end{array}\right. \\
=\left\{\begin{array}{cc}
1, & z_{k}(x) \geq u^{r e j} \\
\frac{z_{k}(x)-l^{r e j}}{u^{r e j}-l^{r e j},} & l^{r e j}<z_{k}(x)<u^{r e j} \\
0, & z_{k}(x) \leq l^{r e j}
\end{array}\right.
\end{gathered}
$$

(iii). Define the membership and non- membership function for the uncertain constraints $\left(\Im_{i n t}\right)$.

$$
\begin{aligned}
& \mu_{i}(A(x))=\left\{\begin{array}{cc}
\frac{t_{i}^{a c c}+b_{i}-A(x)}{t_{i}^{a c c},} & b_{i}<A(x)<b_{i}+t_{i}^{a c c} \\
0, & A(x) \geq b_{i}+t_{i}^{a c c},
\end{array}\right. \\
& v_{i}(A(x))=\left\{\begin{array}{cc}
0, \quad A(x) \leq b_{i}+t_{i}^{r e j} \\
\frac{A(x)-\left(b_{i}+t_{i}^{r e j}\right)}{\left(t_{i}^{a c c}-t_{i}^{r e j}\right)}, & b_{i}<A(x)<b_{i}+t_{i}^{a c c} \\
1, \quad A(x) \geq b_{i}+t_{i}^{a c c}
\end{array}\right.
\end{aligned}
$$

(iv). Define the membership and non- membership function for the uncertain constraints $\left(\gtrsim_{\text {int }}\right)$.

$$
\begin{aligned}
& \mu_{i}(A(x))=\left\{\begin{array}{cc}
1, & A(x) \geq b_{i} \\
\frac{A(x)-\left(b_{i}-t_{i}^{a c c}\right)}{t_{i}^{a c c}}, & b-t_{i}^{a c c}<A(x)<b_{i} \\
0, \quad A(x) \leq b_{i}-t_{i}^{a c c}, & \\
v_{i}(A(x)) & A(x) \geq b_{i}-t_{i}^{r e j}
\end{array}\right. \\
& =\left\{\begin{array}{rrr}
0, & A(x) \geq b_{i}-t_{i}^{r e j} \\
\frac{\left(b_{i}-t_{i}^{r e j}\right)-A(x)}{\left(t_{i}^{a c c}-t_{i}^{r e j}\right)}, & b_{i}-t_{i}^{a c c}< & A(x)<b_{i}-t_{i}^{r e j} \\
1, & A(x) & \leq b_{i}+t_{i}^{a c c}
\end{array}\right.
\end{aligned}
$$


Where $t_{i}^{a c c}, t_{i}^{r e j}=\delta t_{i}^{a c c}, 0<\delta<1$ are tolerances for membership and non-membership function respectively, In our problem, we have taken $\delta=0.1$.

Step 8: In this step we apply intuitionistic fuzzy optimization technique for MOLP problema nd get an equivalent linear programming problem as

$$
\left.\begin{array}{c}
\text { Maximize }(\alpha-\beta) \\
\mu_{k}(x) \geq \alpha, k=1,2, \ldots, p+q \\
v_{k}(x) \leq \beta, k=1,2, \ldots, p+q \\
\alpha+\beta \leq 1 \\
\alpha \geq \beta \\
\beta \geq 0 \\
x \in X
\end{array}\right\}
$$

\section{ILLUSTRATION OF THE \\ PROBLEM:}

Consider a crop planning problem where a farmer can grow rice, til, urd crops in kharif season and can grow wheat, maize, pulse, potato,tilhan in rabi season. The land available is 1.35 acre with given labour hour constraint. Being a smallholder farmer he need atleast 4.42 quintal of rice and 3.42 quintal of wheat necessarily to meet his annual foodgrains requirement as his basic need. Now the problem of the farmer is to plan a suitable crop combination model for each season of rabi and kharif for his land to get maximum profit. And aspiration levels of rupees 78,000 is set to meet his other annual family requirement. The labour availability for each season is given to be 210 man-days. productivity (quintal per acre), labour requirement, investment, for various crops are placed in Table.2. The objective of the problem are to maximize the profit and minimize the investiment and to provide his minimum foodgrain requirement. The computational algorithms developed in section 5 are being implemented step by step to find a optimal solution of the above farmer cro modelling problem.

Table 2.

\begin{tabular}{|l|l|l|l|l|}
\hline Crops & $\begin{array}{l}\text { Labour } \\
\text { (manday } \\
\text { /ha) }\end{array}$ & $\begin{array}{l}\text { Investm } \\
\text { ent } \\
\text { (Rs./ha. }\end{array}$ & $\begin{array}{l}\text { Producti } \\
\text { on } \\
\text { (qt1/ha) }\end{array}$ & $\begin{array}{l}\text { Net profit } \\
\text { (Rs./ha.) }\end{array}$ \\
\hline Kharif & & & & \\
\hline $\begin{array}{l}\text { Rice } \\
\left(x_{1}\right)\end{array}$ & 310 & 5647.00 & 19.64 & 16512.00 \\
\hline Til $\left(x_{2}\right)$ & 75 & 4632.21 & 11.56 & 29426.00 \\
\hline $\begin{array}{l}\text { Urd } \\
\left(x_{3}\right)\end{array}$ & 60 & 2310.76 & 6.56 & 17249.00 \\
\hline Rabi & & 3026.40 & 28.07 & 17504.83 \\
\hline $\begin{array}{l}\text { Wheat } \\
\left(x_{4}\right)\end{array}$ & 190 & 4500.00 & 15.44 & 14856.62 \\
\hline $\begin{array}{l}\text { Maize } \\
\left(x_{5}\right)\end{array}$ & 265 & 2540.76 & 7.82 & 15354.00 \\
\hline $\begin{array}{l}\text { Pulses } \\
\left(x_{6}\right)\end{array}$ & 70 & 4832.06 & 12.30 & 27124.80 \\
\hline $\begin{array}{l}\text { Poitato } \\
\left(x_{7}\right)\end{array}$ & 110 & 6872.62 & 345 & 51054.02 \\
\hline $\begin{array}{l}\text { Tilhan } \\
\left(x_{8}\right)\end{array}$ & 80 & & & \\
\hline
\end{tabular}

The mathematical formulation of the above problem is as:

$$
\begin{gathered}
\text { Maximize } z_{1}=19.64 x_{1}+11.56 x_{2}+6.56 x_{3} \\
+28.07 x_{4}+15.44 x_{5}+ \\
7.82 x_{6}+345 x_{7}+12.30 x_{8} \text { (Production) } \\
\text { Maximize } z_{2}=16512 x_{1}+29426.00 x_{2} \\
+17249.00 x_{3}+17504.83 x_{4}+ \\
14856.62 x_{5}+15354.00 x_{6}+ \\
51054.02 x_{7}+27124.80 x_{8} \quad \text { (Profit) } \\
\text { Minimize } z_{3}=5647.00 x_{1}+4632.21 x_{2} \\
+2310.76 x_{3}+3026.40 x_{4}+ \\
4500.52 x_{5}+2540.76 x_{6}+ \\
6872.62 x_{7}+4832.06 x_{8} \quad \text { (Expanditure) } \\
\text { Food requirement constraints } \\
19.64 x_{1} \geq 4.42 \\
28.07 x_{4} \geq 3.2 \\
\text { Labour constraints } \\
310 x_{1}+75 x_{2}+60 x_{3} \leq 210 \\
190 x_{4}+265 x_{5}+70 x_{6}+ \\
110 x_{7}+80 x_{8} \leq 210 \\
\text { Land constraints } \\
x_{1}+x_{2}+x_{3} \leq 1.35 \\
x_{4}+x_{5}+x_{6}+x_{7}+x_{8} \leq 1.35 \\
x_{j} \geq 0, j=1,2, \ldots, 8 .
\end{gathered}
$$

Using fractional programming approach mentioned in section 4 , we have converted two objectives $\left(z_{2}\right)$ and $\left(z_{3}\right)$ into one objective as $f_{2}(x)$ and we have written $f_{1}(x)=z_{1}(x)$. Thus the problem (16) is reduced to the following fractional programming problem.

$$
\begin{gathered}
\text { Maximize } f_{1}=19.64 x_{1}+11.56 x_{2}+6.56 x_{3} \\
+28.07 x_{4}+15.44 x_{5}+ \\
7.82 x_{6}+345 x_{7}+12.30 x_{8} \\
\text { Maximize } f_{2}=10865 x_{1}+24793.79 x_{2}+ \\
14938.24 x_{3}+14478.43 x_{4}+10356.1 x_{5}+ \\
12813.24 x_{6}+44181.4 x_{7}+22292.74 x_{8} \\
\text { Such that } \\
19.64 x_{1} \geq 4.42 \\
28.07 x_{4} \geq 3.2 \\
310 x_{1}+75 x_{2}+60 x_{3} \leq 210 \\
190 x_{4}+265 x_{5}+70 x_{6}+ \\
110 x_{7}+80 x_{8} \leq 210 \\
x_{1}+x_{2}+x_{3} \leq 1.35 \\
x_{4}+x_{5}+x_{6}+x_{7}+x_{8} \leq 1.35 \\
10865 x_{1}+24793.79 x_{2}+14938.24 x_{3}+ \\
14478.43 x_{4}+10356.1 x_{5}+12813.24 x_{6}+ \\
44181.4 x_{7}+22292.74 x_{8} \geq 0 \\
x_{j} \geq 0, \quad j=1,2, \ldots, 8 .
\end{gathered}
$$

In view of realistic modelling of the above crop planning problem, we consider the inequalities $\left(\lessgtr_{\text {int }}\right)$ as intuitrionistic fuzzy inequalities. The reason for such consideration is quite obvious as the various parameters used in the model such as production, labour, prices and other inputs are in general uncertain. Furthe the production of a crop also depends on many others parameters which are not considered in the model. Now the above MOLPP becomes: 


$$
\begin{gathered}
\text { Find } x \\
\text { Such that } \\
19.64 x_{1}+11.56 x_{2}+6.56 x_{3}+ \\
28.07 x_{4}+15.44 x_{5}+7.82 x_{6}+345 x_{7}+ \\
12.30 x_{8} \gtrsim_{\text {int }} 448.9654 \\
10865 x_{1}+24793.79 x_{2}+14938.24 x_{3}+ \\
14478.43 x_{4}+10356.1 x_{5}+12813.24 x_{6}+ \\
44181.4 x_{7}+22292.74 x_{8} \gtrsim_{\text {int }} 86596 \\
9.64 x_{1} \gtrsim_{\text {int }} 4.42 \\
28.07 x_{4} \gtrsim_{\text {int }} 3.2 \\
190 x_{4}+265 x_{5}+70 x_{6}+110 x_{7}+80 x_{8} \lessgtr_{\text {int }} 210 \\
x_{1}+x_{2}+x_{3} \leq 1.35 \\
x_{4}+x_{5}+x_{6}+x_{7}+x_{8} \leq 1.35 \\
10865 x_{1}+24793.79 x_{2}+14938.24 x_{3}+ \\
14478.43 x_{4}+10356.1 x_{5}+12813.24 x_{6}+ \\
44181.4 x_{7}+22292.74 x_{8} \geq 0, \\
x_{j} \geq 0, \quad j=1,2, \ldots, 8 .
\end{gathered}
$$

The above problem (18) have beentransformed to a linear programming problem using step (7)and (8) of computational algoriths presented in section and the resulting linear programming problem has been solved using Matlab. The results for the optimal crop planning model for area of different crops (in acre) is as follows:

area for rice in kharif : $x_{1}=0.3056$

area for til in kharif: $x_{2}=1.0444$

area for urd in kharif : $x_{3}=0.0000$

area for wheat in rabi: $x_{4}=0.1114$

area for maize in rabi : $x_{5}=0.0000$

area for pulses in rabi : $x_{6}=0.0000$

area for potato in rabi : $x_{7}=1.2386$

area for tilhan in rabi : $x_{8}=0.0000$

Degree of acceptance : $\alpha=0.7704$

Degree of rejection : $\beta=0.1440$.

The values obtained for the maximal objective functions are given in table 3 .

Table 3.

\begin{tabular}{|l|l|}
\hline Objective functions & Values of objective function \\
\hline Maximum profit $\left(z_{1}^{o}\right)$ & 100964.12 Rupees/year \\
\hline Minimumexpenditure $\left(z_{2}^{o}\right)$ & 15413.17 Rupees/year \\
\hline Maximum production $\left(z_{3}^{o}\right)$ & 448.5192 quntals/year \\
\hline
\end{tabular}

\section{CONCLUSION}

Here, we have considered objective functions and constraints as intuitionistic fuzzy inequalities to model the formers crop planning problems in realistic situations as the production or profit cannot be set as crisp inequalities due to imprecision in parameters. Thus MOLP problems become IFMOLP problem in a natural way. We have applied intuitionistic fuzzy approach to convert a IFMOLP problem into crisp linear programming problem using developed algorithms. The developed algorithm has been implemented to obtain an optimal crop production model. The results obtained by developed method are interesting as it satisfy the constraints and achieve the set goals in an optimal way by utilizing maximum land area available with the farmer. Further, the developed model provides more profit to farmer to a tune of Rs. 100964.12 to farmer aspiration level of Rs. 78,000. Thus the proposed method can be used for handling the crop modeling problems in an effective way.

\section{ACKNOWLEDGEMENTS}

The author are thankful to University Grants Commission (U.G.C), New Delhi, INDIA, for financial support for research work.

\section{REFERENCES}

1. Atanassov, K.T. "Intuitionistic fuzzy sets", Fuzzy Sets and Systems, Vol.20 pp.87-96, 1986.

2. Atanassov, K.T. "Interval valued intuitionistic fuzzy sets”, Fuzzy Sets and Systems, vol.31, pp.343-349, 1989.

3. Angelov, P. P., "Optimization in an intuitionistic fuzzy environment", Fuzzy Sets and Systems, vol. 86, pp. 299306, 1997.

4. B. Jana, Roy, T.K., "Multi objective intuitionistic fuzzy linear programming and its application in transportation model", NIFS vol.13, no.1, pp. 1-18, 2007.

5. Bellman, R.E., Zadeh, L.A. "Decision making in a fuzzy environment", Management Science, vol.17, pp.B141B164, 1970.

6. Bharati, S. K. and Singh, S.R., Solving Multi-Objective Linear Programming Problems Using Intuitionistic Fuzzy Environment Optimization Method: a Comparative Study, International Journal of Modeling and Optimization, DOI: 10.7763/IJMO.2014.V4.339.

7. Bharati, S. K., Nishad. A. K., Singh, S. R. Solution of Multi-Objective Linear Programming Problems in Intuitionistic Fuzzy Environment, Proceedings of the Second International Conference on Soft Computing for Problem Solving (SocProS 2012), December 28-30, 2012, Advances in Intelligent Systems and Computing 236, DOI: 10.1007/978-81-322-1602-5_18, C C Springer India 2014.

8. Dubey Dipti, Mehra Aparna "Linear programming with Triangular Intuitionistic Fuzzy Number", EUSFLATLFA 2011, Advances in Intelligent Systems Research, Atlantis Press, vol.1 , no.1, pp. 563-569,2011.

9. Dubey, Dipti, Chandra, Suresh, Mehra, Aparna, "Fuzzy linear programming under interval uncertainty based on IFS representation", Fuzzy Sets and Systems, vol.188 no.1, pp. 68-87, 2012.

10. Garg A, Singh S R, Optimization under uncertainty in agricultural production planning, iconcept pocket journal: Computational Intelligence for Financial Engineers:1(1) 2010,1-12.

11. Luhandjula, M., "Fuzzy optimization: an appraisal", Fuzzy Sets and Systems, vol.30, pp. 257-288, 1988.

12. Mahapatra, G.S. Mitra, M. Roy, T.K, "Intuitionistic fuzzy multiobjective mathematical programming on 
reliability optimization model", International Journal of Fuzzy Systems, vol.12, no.3, pp.259-266, 2010.

13. Nachammai, A. L., Thangaraj, $P$ "Solving intuitionistic fuzzy linear programming problem by using similarity measures", European Journal of Scientific Research, vol. 72, no.2, pp. 204-210, 2012.

14. Nagoorgani, P.K. "A new approach on solving intuitionistic fuzzy linear programming problem", Applied Mathematical Sciences, vo. 6, no.70,pp. 34673474,2012 .

15. Sarkar Rahul A, Talukdar S, Haque A. F. M. A., Determinatuion of optimal crop mix for crop cultivation in Bangladesh, Appl. Math. Modeling 21, pp 621$632,1997$.

16. Sharma, D.K., Jana R.K., Gaur A, Fuzzy goal programming for Agricultural Land alloacation problems, Yogslave journal of operations research, 17 pp 31-42, 2007.

17. Sinha P., Analysis of optimal crop combination under limited resourse allocation: Goal programming approach to smallholder farmers in North Bihar, $\mathrm{Ph}$. D. Thesis, Banasthali University India, 2013.
18. Tanaka, H. Asai, K "Fuzzy linear programming problems with fuzzy numbers", Fuzzy Sets and Systems, vol.139, pp.1-10, 1984.

19. Takeshi Itoh, Ishii H, Nauseki T, A model of crop planning under uncertainty in agricultural management , Int. J. Production Economics, 81-82 pp555-558,2003.

20. Toyonaga T. Itoh T., Ishii H. A crop planning problem with fuzzy random profit coefficients, fuzzy optimization and decision making, 4 pp 51-69, 2005.

21. Yan Luo, Changrui Yu, "An fuzzy optimization method for multi criteria decision making problem based on the inclusion degrees of intuitionistic fuzzy set", Journal of Information and Computing Science, vo. 3, no.2,pp146152,2008 .

22. Zadeh, L.A., "Fuzzy Sets", Information and control, vol.8, pp.338-353, 1965.

23. Zimmermann, H.J., "Fuzzy programming and linear programming with several objective functions", Fuzzy Sets and Systems, vol.1, pp.45-55, 1978. 